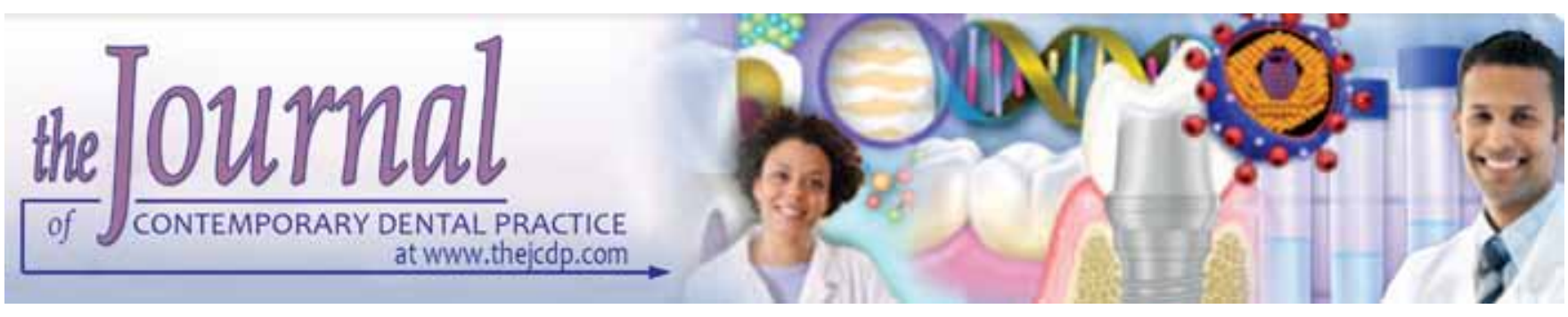

\title{
The Antibacterial Properties of Composite Resin Containing Nanosilver against Streptococcus mutans and Lactobacillus
}

\author{
Mohadese Azarsina, Shahin Kasraei, Rasoul Yousefi-Mashouf, Nima Dehghani, Mehdi Shirinzad
}

\section{ABSTRACT}

Aim: The aim was to evaluate the antibacterial properties of composite resin containing nanosilver against Streptococcus mutans (SM) and Lactobacillus (L).

Materials and methods: Nanosilver was added to Z250 composite at 0.5 and $1 \%$ by weight. In order to confirm the homogenous distribution of the nanoparticles in the composite resin, SEM-EDX analysis was performed on one sample in each group. Z250 composite without nanosilver was used as control. Direct contact test was used to test the antibacterial properties of nanoparticle-loaded composites: $0.001 \mathrm{ml}$ of 0.5 Mc Farland suspension of MS and $L$ was placed on composite disks, and incubated for 1 hour in 5 to $10 \% \mathrm{CO}_{2}$ incubator at $37^{\circ} \mathrm{C}$. Samples were placed in $0.5 \mathrm{ml}$ of sterile $\mathrm{BHI}$ broth and incubated for 2 hours in $\mathrm{CO}_{2}$ incubator. Afterwards, $0.001 \mathrm{ml}$ liquid from each medium was distributed on blood agar plates and incubated for 48 hours in $\mathrm{CO}_{2}$ incubator. The numbers of bacterial colonies were counted visually. Data were analyzed using Two-way ANOVA and Tukey HSD test. Significance level was set at 0.05 .

Results: Addition of nanosilver to composite resin had a significant effect on reduction of the number of $S M$ and $L$ colonies $(p=0.000)$. The antibacterial properties of composite resins are different depending on the concentration of nanosilver $(p=0.014)$. Tukey test indicated that increase in the concentration of nanosilver caused the increase in antibacterial properties of composite resin.

Conclusion: Addition of silver nanoparticles to Z250 composite could significantly inhibit the growth of Streptococcus mutans and Lactobacillus on the surface of this composite.

Clinical significance: The addition of nanosilver to Z250 composite could inhibit the growth of SM and L on the surface of the restoration and therefore prevent the occurrence of secondary caries.

Keywords: Composite resin, Streptococcus mutans, Lactobacillus, Nanotechnology, Laboratory research.

How to cite this article: Azarsina M, Kasraei S, YousefiMashouf R, Dehghani N, Shirinzad M. The Antibacterial Properties of Composite Resin Containing Nanosilver against Streptococcus mutans and Lactobacillus. J Contemp Dent Pract 2013;14(6):1014-1018.

\section{Source of support: Nil}

Conflict of interest: None

\section{INTRODUCTION}

Although the mechanical properties of methacrylatebased composite resin restorations have been improved substantially, their antibacterial properties are still limited. The bacterial accumulation on the surfaces of these restorative materials can provide the bacterial source leading to the development of secondary caries and periodontal diseases. ${ }^{1,2}$ Microorganisms accumulate more readily on composite resins compared to amalgam and glass ionomer restoratives. ${ }^{3}$

Various researchers have attempted to reduce plaque accumulation on the surfaces of dental materials by incorporation of bactericidal agents such as chlorhexidine, ${ }^{4}$ antibacterial monomer MDPB, ${ }^{5,6}$ antibacterial monomer furanone $^{7}$ and other antibacterial fillers. ${ }^{8}$

Silver has a significant antimicrobial activity and is effective against streptococci of the human oral cavity and periodontal pathogens ${ }^{9}$ so, it might be useful as an antibacterial agent incorporated into dental restorations, especially when applied in nanometer sizes.

Cytotoxicity of silver nanoparticles on fungi, protozoa, some viruses and bacteria including Staphylococcus aureus, Streptococcus mutans, Lactobacillus and Escherichia coli is approved in previous studies. ${ }^{10-13}$ Considering the fact that silver is effective against the Streptococci of the oral flora and periodontal pathogens, and inhibits bacterial adherence to surfaces and biofilm formation, it can be applied as a useful antibacterial additive to dental restorations. ${ }^{9,14}$

The addition of silver filler particles has been stated to have a very good protective effect against $S$. mutans. ${ }^{15,16}$ 
Evaluation of the effect of loading the composite resin restorations with nanoparticles might be effective in reduction of plaque accumulation.

Since Streptococcus mutans and Lactobacillus are the main bacteria responsible in tooth carious process, ${ }^{17}$ the present study was designed to evaluate the antibacterial effect of composite resin containing nanosilver against Streptococcus mutans and Lactobacillus.

The null hypothesis of the study is that the addition of nanosilver to composite resin does not have any antibacterial effect against Streptococcus mutans and Lactobacillus.

\section{MATERIALS AND METHODS}

In this in vitro study, nanosilver particles (TopNano Tech Co. Taipei, Taiwan) with average size of $50 \mathrm{~nm}$ were added mechanically to Z250 (3M ESPE, St Paul, MN, USA) composite at 0.5 and $1 \%$ by weight. The nanoparticles were mixed with the composite resin by a plastic spatula continuously for 30 minutes in a dark room. In order to confirm the homogenous distribution of the nanoparticles in the composite resin, SEM-EDX (Scanning electron microscopy with an energy dispersive X-ray analytical system) analysis was performed on one sample in each group. One sample in each group was made in PVC molds of $4 \mathrm{~mm}$ diameter and $1.5 \mathrm{~mm}$ height. The composite was inserted into the mold and immediately covered with two glass slides from the top and the bottom. The specimen was polymerized using an LED (Demi LED Light Curing System, Kerr Corp, Orange, CA, USA) light-curing unit with a light intensity of $800 \mathrm{~mW} / \mathrm{cm}^{2}$ from both sides. Samples were broken into two pieces with a chisel-like blade and the broken surfaces were gold sputter coated (Sputter coater, EMITECH, K45OX Ashford; Kent, England) in a thin $15 \mathrm{~nm}$ layer to prevent the samples' surfaces from burning during SEM observation. The elemental gold was finally eliminated from the diagram by the system software. The broken surfaces of each sample were observed with a scanning electron microscope (TESCAN,VEGAII, XMU, Zech Republic) at $\times 350$ (Fig. 1). Following confirmation of the homogenous distribution of the nanoparticles into the composites, the samples of each study group were made by the same method as described above in PVC molds ( $\mathrm{N}=12)$. $\mathrm{Z} 250$ composite resin without nanosilver addition was used as control. All of the samples were polished with 600,800 , 1200 grit SiC papers (991A softlex, Germany) to obtain highly polished samples with identical surface roughness (Ra) values.

Direct contact test was used to test the antibacterial properties of nanoparticle-loaded composites: Initially, Streptococcus mutans bacterial suspension [Persian type culture collection $(\mathrm{PTCC})=1683$ ] and Lactobacillus bacterial suspension $(\mathrm{PTCC}=1643)$ in brain-heart infusion (BHI) with concentration of $0.5 \mathrm{Mc}$ Farland were prepared ( $1 \mathrm{ml}$ that contains about $1.5 \times 10^{8}$ bacteria). $0.001 \mathrm{ml}$ of $0.5 \mathrm{Mc}$ Farland suspension was extracted with a sterile sampler and placed on composite disks which were sterilized in autoclave and incubated for 1 hour in 5 to $10 \% \mathrm{CO}_{2}$ incubator at $37^{\circ} \mathrm{C}$. During that period, the suspension liquid evaporated, ensuring direct contact between bacteria and the composite disk surface. Samples were placed in $0.5 \mathrm{ml}$ of sterile BHI broth and incubated for 2 hours in 5 to $10 \% \mathrm{CO}_{2}$ incubator at $37^{\circ} \mathrm{C}$. Afterwards, $0.001 \mathrm{ml}$ liquid from each medium was extracted with a sampler and distributed on blood agar plates (merch, Damstadt, Germany) and incubated for 48 hours in
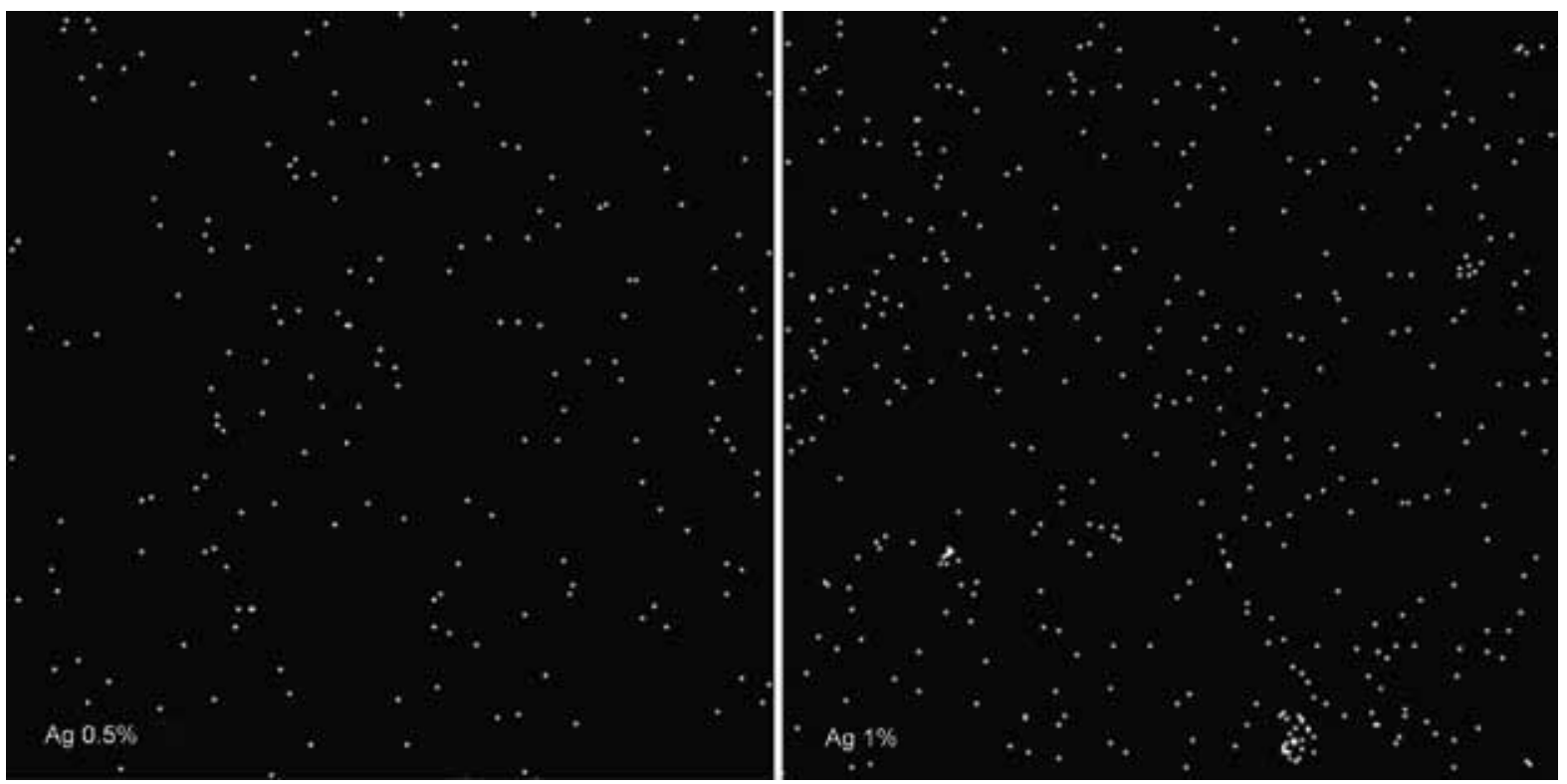

Fig. 1: SEM-EDX image of the surface of composites containing $0.5,1 \%$ nanosilver particles 
5 to $10 \% \mathrm{CO}_{2}$ incubator at $37^{\circ} \mathrm{C}$. The numbers of bacterial colonies were counted visually.

Data were analyzed using Two-way ANOVA and Tukey HSD multiple comparisons. Significance level was set at 0.05 .

\section{RESULTS}

Mean and SD of the studied groups for bacterial counts are summerized in Table 1. The highest amount of bacterial growth was seen in control groups (Streptococcus mutans $=$ $209.83 \pm 99.50$, Lactobacillus $=64.58 \pm 41.61$, whereas the lowest amount of bacteria had grown on samples containing $1 \%$ Ag nanoparticles (Streptococcus mutans $=127.08 \pm$ 70.35 , Lactobacillus $=32.16 \pm 22.95$ ).

Analysis of variance indicated that addition of silver nanoparticles to composite resin had a significant effect on reduction of the number of SM and $\mathrm{L}$ bacterial colonies $(p=0.000)$. It was also indicated that the antibacterial properties of composite resins are different depending on the concentration of nanosilver particles $(p=0.014)$. The antibacterial effect of composites containing nanosilver was significant depending on the type of the bacteria $(p=0.001)$. However, the interaction of the concentration of nanoparticle and the type of bacteria was not statistically significant $(\mathrm{p}=0.327)$.

The comparison of the control and test groups by Tukey HSD test indicated that increase in the concentration of nanosilver causes the increase in antibacterial properties of composite resin (Table 2).

\section{DISCUSSION}

Application of nanoparticles of silver is increasingly growing in medicine and industry for their antibacterial properties ${ }^{18,19}$ Sorption of microorganisms by the composite resins occurs more often than other restorative materials; ${ }^{3,20}$ therefore, we added silver nanoparticles to a composite resin to provide antibacterial properties for this restorative material.
Some studies have used agar disk diffusion to evaluate antibacterial properties of cured composite resins. In this method composite disks are placed on agar plates containing Streptococcus mutans and Lactobacillus; $;{ }^{21-23}$ however, considering that mano-posticle containing composites are not supposed to release any antibacterial material and do not create any growth inhibition halo, this method is not suitable for evaluation of bactericidal properties of composite resins. ${ }^{22-24}$ Therefore, the present study performed direct contact method and BHI-broth medium to study the antibacterial properties of composite resin disks; and considering the fact that liquid medium contains both live and dead bacteria, in order to trace and count the live and active colonies, $0.001 \mathrm{ml}$ from each bacterial suspension tube was cultured on blood agar medium.

The results of the present study indicated that the amount of bacterial colonies was significantly higher in control groups compared to test groups. The bactericidal potential of Z250 composite containing nanosilver particles was considerably observed.

Most of the previous studies confirm the antibacterial properties of nanosilver incorporated into composite resins; however they have reported different concentrations and effectiveness for these particles. ${ }^{15,25,26}$ Hernández-Sierra et al ${ }^{27}$ evaluated the sensitivity of Streptococcus mutans to nano particles of silver $(25 \mathrm{~nm})$, zinc oxide $(125 \mathrm{~nm})$ and gold $(80 \mathrm{~nm})$ and indicated the higher antibacterial properties of nano silver than nano zinc oxide and nanogold; they attributed this results to smaller particle size of nanosilver than nano zinc oxide particles.

Concerns exist about the adverse effect of nanoparticle additives on the mechanical properties of composite resins; however, previous studies have reported silver compounds added in $10 \%$ concentration or greater to dental materials would significantly reduce compressive strength, elastic modulus and tensile strength. 8,28 Therefore, it seems that nanoparticles added in low concentrations as in the present study would not adversely affect mechanical properties of composite resins.

Table 1: Mean and SD of bacterial count of mutans and Lactobacillus in $0.001 \mathrm{ml}$ of liquid medium in control and tests groups

\begin{tabular}{|c|c|c|c|c|c|c|c|c|c|c|}
\hline \multirow[t]{2}{*}{ Groups } & \multicolumn{5}{|c|}{ Streptococcus mutans } & \multicolumn{5}{|c|}{ Lactobacillus } \\
\hline & Number & Mean & $S D$ & Min. & Max. & Number & Mean & $S D$ & Min. & Max. \\
\hline Control & 12 & 209.83 & 99.50 & 97 & 363 & 12 & 64.58 & 41.61 & 23 & 128 \\
\hline $\operatorname{Ag~} 0.5 \%$ & 12 & 190.00 & 98.74 & 68 & 335 & 12 & 44.00 & 17.48 & 7 & 73 \\
\hline Ag $1 \%$ & 12 & 127.08 & 70.35 & 43 & 313 & 12 & 32.16 & 22.95 & 6 & 74 \\
\hline
\end{tabular}

\begin{tabular}{lccc} 
& \multicolumn{2}{c}{ Table 2: Pairwise comparison of the effect of nanosilver addition to composite resin } \\
\hline Nanosilver percent & Nanosilver percent & Mean difference & Significance $^{*}$ \\
\hline $0 \%$ & $0.5 \%$ & 40.9271 & 0.000 \\
$0 \%$ & $1 \%$ & 79.2396 & 0.000 \\
$0.5 \%$ & $1 \%$ & 38.3125 & 0.000 \\
\hline
\end{tabular}

\footnotetext{
*:Tukey HSD test
} 
The composites used in this study were not mixed with the nanoparticles by a mechanical mixer, due to their high viscosity. The manual incorporation of the nanoparticles into the composite resin may include air bubbles into the composite, which might affect some of its properties. Although the composites were completely packed into the molds during sample preparation, and despite the observation that these possible porosities did not have any deleterious effect on the antibacterial properties of the studied composites, it might have affected the mechanical properties. Therefore, it is suggested that this step be done in vacuum or by a special machine designed for mixing of such highly viscose materials.

Discoloration and grayish color change is a common problem in all materials containing silver, especially composite resins. ${ }^{29}$ It has been reported in a previous study that the 0.3 and $0.6 \%$ concentration of silver microparticulates incorporated into the composite resin had the respective antibacterial properties. Therefore, according to previous studies, we chose the 0.5 and $1 \%$ concentration of silver nanoparticles to benefit both the antibacterial properties of silver and the less detrimental effect of these nanoparticles on the color of composite resins.

Composites containing nanosilver particles can be applied in restorative and orthodontic treatments and longterm splinting of the teeth. ${ }^{30,31}$ In spite of using fluoride and glass ionomer particles in composite restorations, it seems using composite resin cements containing antibacterial materials would be useful for reducing caries activity around orthodontic brackets. ${ }^{8,32,33}$ Failure of posterior class II composite restorations due to microleakage and secondary caries can be prevented by using these bactericidal composites as liners under final restorations. In this way, we can benefit the antibacterial properties of these composite resins, while masking their grayish color by conventional composites.

Considering the importance of using antibacterial restorative materials, it is suggested that studies be performed on other antibacterial materials which have less detrimental esthetic effects on composite resins.

\section{CONCLUSION}

Within the limitations of the present study, it was concluded that the addition of silver nanoparticles to Z250 composite could significantly inhibit the growth of Streptococcus mutans and Lactobacillus on the surface of this composite.

\section{Clinical significances}

Nanosilver incorporated into composite resins inhibited the growth of Streptococcus mutans and Lactobacillus on the surface of the restoration and therefore can prevent the occurrence of secondary caries.

\section{ACKNOWLEDGMENTS}

The authors thank the Dental Research Center and Vice Chancellor of Research, Hamadan University of Medical Sciences, for supporting this study.

\section{REFERENCES}

1. Cruz AD, Cogo K, Bergamaschi Cde C, Bóscolo FN, Groppo FC, Almeida SM. Oral streptococci growth on aging and nonaging esthetic restorations after radiotherapy. Braz Dent J 2010; 21(4): 346-350.

2. Montanaro L, Campoccia D, Rizzi S, Donati ME, Breschi L, Prati C, Arciola CR. Evaluation of bacterial adhesion of Streptococcus mutans on dental restorative materials. Biomaterials 2004 Aug; 25(18):4457-4463.

3. Papagiannoulis L, Kakaboura A, Eliades G. In vivo vs in vitro anticariogenic behavior of glass-ionomer and resin composite restorative materials. Dent Mater 2002 Dec;18(8):561-569.

4. Mehdawi I, Neel EA, Valappil SP, Palmer G, Salih V, Pratten J, Spratt DA, Young AM. Development of remineralizing, antibacterial dental materials. Acta Biomater 2009 Sep;5(7): 2525-2539.

5. Imazato S, Russell RR, McCabe JF. Antibacterial activity of MDPB polymer incorporated in dental resin. J Dent 1995 Jun; 23(3):177-181.

6. Thomé T, Mayer MP, Imazato S, Geraldo-Martins VR, Marques MM. In vitro analysis of inhibitory effects of the antibacterial monomer MDPB-containing restorations on the progression of secondary root caries. J Dent 2009 Sep;37(9):705-711.

7. Weng Y, Howard L, Guo X, Chong VJ, Gregory RL, Xie D. A novel antibacterial resin composite for improved dental restoratives. J Mater Sci Mater Med 2012 Jun; 23(6):1553-1561.

8. Syafiuddin T, Hisamitsu H, Toko T, Igarashi T, Goto N, Fujishima A, Miyazaki T. In vitro inhibition of caries around a resin composite restoration containing antibacterial filler. Biomaterials 1997 Aug;18(15):1051-1057.

9. Spacciapoli P, Buxton D, Rothstein D, Friden P. Antimicrobial activity of silver nitrate against periodontal pathogens. J Periodontal Res 2001 Apr;36(2):108-113.

10. Martinez-Gutierrez F, Olive PL, Banuelos A, Orrantia E, Nino N, Sanchez EM, Ruiz F, Bach H, Av-Gay Y. Synthesis, characterization, and evaluation of antimicrobial and cytotoxic effect of silver and titanium nanoparticles. Nanomedicine 2010 Oct;6(5):681-688.

11. Sondi I, Salopek-Sondi B. Silver nanoparticles as antimicrobial agent: a case study on E. coli as a model for gram-negative bacteria. J Colloid Interface Sci 2004 Jul;275(1):177-182.

12. Kim JS, Kuk E, Yu KN, Kim JH, Park SJ, Lee HJ, Kim SH, Park YK, Park YH, Hwang CY, Kim YK, Lee YS, Jeong DH, Cho MH. Antimicrobial effects of silver nanoparticles. Nanomedicine 2007 Mar;3(1):95-101.

13. Monteiro DR, Gorup LF, Takamiya AS, Ruvollo-Filho AC, de Camargo ER, Barbosa DB. The growing importance of materials that prevent microbial adhesion: antimicrobial effect of medical devices containing silver. Int J Antimicrob Agents 2009 Aug; 34(2):103-110.

14. Balazs DJ, Triandafillu K, Wood P, Chevolot Y, van Delden C, Harms H, Hollenstein C, Mathieu HJ. Inhibition of bacterial 
adhesion on PVC endotracheal tubes by RF-oxygen glow discharge, sodium hydroxide and silver nitrate treatments. Biomaterials 2004 May;25(11):2139-2151.

15. Yoshida K, Tanagawa M, Atsuta M. Characterization and inhibitory effect of antibacterial dental resin composites incorporating silver-supported materials. J Biomed Mater Res 1999 Dec 15;47(4):516-522.

16. Cheng L, Zhang K, Weir MD, Liu H, Zhou X, Xu HH. Effects of antibacterial primers with quaternary ammonium and nanosilver on Streptococcus mutans impregnated in human dentin blocks. Dent Mater 2013 Apr;29(4):462-472.

17. Matalon S, Weiss EI, Gorfil C, Noy D, Slutzky H. In vitro antibacterial evaluation of flowable restorative materials. Quintessence Int 2009 Apr;40(4):327-332.

18. Sahoo SK, Parveen S, Panda JJ. The present and future of nanotechnology in human health care. Nanomedicine 2007 Mar; 3(1):20-31.

19. Rai M, Yadav A, Gade A. Silver nanoparticles as a new generation of antimicrobials. Biotechnol Adv 2009 Jan-Feb;27(1):76-83.

20. Svanberg M, Mjör IA, Orstavik D. Mutans streptococci in plaque from margins of amalgam, composite and glass-ionomer restorations. J Dent Res 1990 Mar;69(3):861-864.

21. Kumar R, Münstedt H. Silver ion release from antimicrobial polyamide/silver composites. Biomaterials 2005 May;26(14): 2081-2088.

22. Imazato S. Antibacterial properties of resin composites and dentin bonding systems. Dent Mater 2003 Sep;19(6):449-457.

23. Tavassoli Hojati S, Alaghemand H, Hamze F, Ahmadian Babaki F, Rajab-Nia R, Rezvani MB, Kaviani M, Atai M. Antibacterial, physical and mechanical properties of flowable resin composites containing zinc oxide nanoparticles. Dent Mater 2013 May;29(5): 495-505.

24. Bundy KJ, Butler MF, Hochman RF. An investigation of the bacteriostatic properties of pure metals. J Biomed Mater Res 1980 Sep;14(5):653-663.

25. Yoshida K, Tanagawa M, Matsumoto S, Yamada T, Atsuta M. Antibacterial activity of resin composites with silver-containing materials. Eur J Oral Sci 1999 Aug;107(4):290-296.

26. Zhang K, Cheng L, Imazato S, Antonucci JM, Lin NJ, Lin-Gibson S, Bai Y, Xu HH. Effects of dual antibacterial agents MDPB and nanosilver in primer on microcosm biofilm, cytotoxicity and dentine bond properties. J Dent 2013 May;41(5):464-474.

27. Hernández-Sierra JF, Ruiz F, Pena DC, Martínez-Gutiérrez F, Martínez AE, Guillén Ade J, Tapia-Pérez H, Castañón GM. The antimicrobial sensitivity of Streptococcus mutans to nanoparticles of silver, zinc oxide and gold. Nanomedicine 2008 Sep;4(3): 237-240.
28. Burgers R, Eidt A, Frankenberger R, Rosentritt M, Schweikl H, Handel G, Hahnel S. The anti-adherence activity and bactericidal effect of microparticulate silver additives in composite resin materials. Arch Oral Biol 2009 Jun;(54):595-601.

29. Chen X, Schluesener HJ. Nanosilver: a nanoproduct in medical application. Toxicol Lett 2008 Jan 4;176(1):1-12.

30. Schmidlin PR, Schätzle M, Fischer J, Attin T. Bonding of brackets using a caries-protective adhesive patch. J Dent 2008 Feb;36(2): 125-129.

31. Dubroc GC Jr, Mayo JA, Rankine CA. Reduction of caries and of demineralization around orthodontic brackets: effect of a fluoridereleasing resin in the rat model. Am J Orthod Dentofacial Orthop 1994 Dec;106(6):583-587.

32. Thomé T, Mayer MP, Imazato S, Geraldo-Martins VR, Marques MM. In vitro analysis of inhibitory effects of the antibacterial monomer MDPB-containing restorations on the progression of secondary root caries. J Dent 2009 Sep;37(9):705-711.

33. Pascotto RC, Navarro MF, Capelozza Filho L, Cury JA. In vivo effect of a resin-modified glass ionomer cement on enamel demineralization around orthodontic brackets. Am J Orthod Dentofacial Orthop 2004 Jan;125(1):36-41.

\section{ABOUT THE AUTHORS}

\section{Mohadese Azarsina}

Assistant Professor, Department of Operative Dentistry, Dental School International Branch of Shahid Beheshti University of Medical Sciences, Iran

\section{Shahin Kasraei}

Associate Professor, Department of Operative Dentistry, Dental Research Center, Hamadan University of Medical Sciences, Iran

\section{Rasoul Yousefi-Mashouf}

Full Professor, Department of Microbiology, Medical School, Hamadan University of Medical Sciences, Iran

\section{Nima Dehghani}

Postgraduate Student, Department of Oral and Maxillofacial Surgery Dental School, Shahid Beheshti University of Medical Sciences, Iran

\section{Mehdi Shirinzad (Corresponding Author)}

Assistant Professor, Department of Operative Dentistry, Dental School Hamadan University of Medical Sciences, Iran, e-mail: mshirinzad@ ymail.com 